\title{
Transcriptionally Inactive Oocyte-Type 5S RNA Genes of Xenopus laevis Are Complexed with TFIIIA In Vitro
}

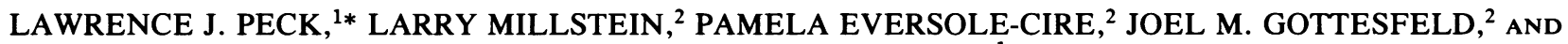 \\ ALEXANDER VARSHAVSKY ${ }^{1}$ \\ Department of Biology, Massachusetts Institute of Technology, Cambridge, Massachusetts 02139, ${ }^{1}$ and Department of \\ Molecular Biology, Research Institute of Scripps Clinic, La Jolla, California $92037^{2}$
}

Received 27 March 1987/Accepted 3 July 1987

\begin{abstract}
An extract from whole oocytes of Xenopus laevis was shown to transcribe somatic-type 5S RNA genes $\sim$ 100-fold more efficiently than oocyte-type 5S RNA genes. This preference was at least 10-fold greater than the preference seen upon microinjection of 5S RNA genes into oocyte nuclei or upon in vitro transcription in an oocyte nuclear extract. The $\sim \mathbf{1 0 0}$-fold transcriptional bias in favor of the somatic-type 5S RNA genes observed in vitro in the whole oocyte extract was similar to the transcriptional bias observed in developing Xenopus embryos. We also showed that in the whole oocyte extract, a promoter-binding protein required for 5S RNA gene transcription, TFIIIA, was bound both to the actively transcribed somatic-type 5S RNA genes and to the largely inactive oocyte-type 5S RNA genes. These findings suggest that the mechanism for the differential expression of 5S RNA genes during Xenopus development does not involve differential binding of TFIIIA to 5S RNA genes.
\end{abstract}

The genome of the frog Xenopus laevis contains two distinct families of genes for 5S RNA, the smallest RNA component of the ribosome. In the developing oocyte of this amphibian, genomic 5S RNA genes of both families are actively transcribed, yielding large amounts of stored $5 \mathrm{~S}$ RNA for subsequent ribosome production during embryogenesis. The oocyte-type family of 5S RNA genes, with approximately 20,000 copies per haploid genome, is transcribed during oogenesis but is relatively inactive during embryogenesis and is switched off in somatic cells. In contrast, the somatic-type family of 5S RNA genes, with approximately 400 copies per haploid genome, is transcribed during both oogenesis and embryogenesis and is also active in somatic cells. Transcription of Xenopus 5S RNA genes has been extensively studied both in vitro and in vivo, in part because these genes provide a well-defined example of differential regulation of gene expression during development $(5,6,16)$.

Like other genes transcribed by RNA polymerase III, such as the tRNA genes, 5S RNA genes require factors TFIIIB and TFIIIC for transcription $(26,29)$. Unlike the tRNA genes, however, transcription of 5S RNA genes requires an additional factor, TFIIIA (8). This protein has been purified to homogeneity and extensively studied $(1,11$, 23). The first step in the kinetic pathway for the transcription of 5S RNA genes involves the binding of TFIIIA to the internal control region within the 120-base-pair 5S RNA coding sequence. The mode of DNA binding by TFIIIA is thought to involve multiple $\mathrm{Zn}^{2+}$-stabilized domains of TFIIIA, each of the domains interacting with a specific stretch of DNA approximately 5 base pairs long (21). After formation of a complex between TFIIIA and the 5S RNA gene, the other transcription factors, TFIIIC and TFIIIB, can bind in turn, forming a stable transcription complex which in the presence of RNA polymerase III is capable of directing multiple rounds of transcription of the 5S RNA gene $(4,18,27)$.

\footnotetext{
* Corresponding author.
}

Whereas the nucleotide sequences flanking the oocytetype and somatic-type 5S RNA genes are strikingly different from each other, the corresponding coding sequences differ in only a few positions out of the 120 base pairs (see Fig. 1). So far, no functional differences have been detected between the oocyte-type and somatic-type 5S RNAs. The few nucleotide sequence differences between the coding regions of the corresponding genes are sufficient, however, to result in slightly different affinities of TFIIIA for the two types of 5S RNA genes $(24,33)$. The approximately fivefold greater affinity of TFIIIA for somatic over oocyte 5S RNA genes is the basis for current models of the differential expression of these two gene families during development. The models invoke mechanisms to amplify this difference in binding affinity observed in vitro such that the ratio of TFIIIA actually bound to the two types of 5S RNA genes in vivo would reflect the ratio of their observed transcription rates $(4,7,9,13,25)$. One implicit assumption in these models is that 5S RNA genes with bound TFIIIA will be actively transcribed in an environment that supplies all other necessary components of the transcription complex.

The results of the present work indicate that binding of TFIIIA to an oocyte 5S RNA gene is not always sufficient to activate transcription of that gene even in the presence of all of the components necessary for transcription of 5S RNA genes. Specifically, under in vitro transcription conditions, in which somatic 5S RNA genes are transcribed but oocyte 5S RNA genes are largely inactive, we show that TFIIIA is bound to the internal control regions of both genes. This result implies that the differential expression of 5S RNA genes is not directly controlled by the relative occupancy of the internal control regions of these genes with TFIIIA.

\section{MATERIALS AND METHODS}

Plasmid constructions. All inserts were cloned either into the HindIII site or between the HindIII and EcoRI sites of the vector $\mathrm{pJW} 1+4$. This vector (provided by James Wang) was constructed by combining fragments 1 and 4 from a Haell digest of pBR322 and represents pBR322 with base 
pairs 235 through 2351 deleted. The orientation of all inserts is the same and is such that transcription of the 5S RNA genes is in the same direction as transcription of the bla gene in the vector. Plasmid s (somatic), a representative of the family of somatic 5S RNA genes, contains the HindIII insert from pXls11 (2). Plasmid $o \psi$, a representative of the family of oocyte 5S RNA genes, contains the HindIII insert from pXlo31 (20). Bogenhagen and Brown (3) removed the pseudogene from pXlo31 to produce pXlo $\Delta 3^{\prime}+176$. Moving the HindIII-EcoRI insert from pXlo $\Delta 3^{\prime}+176$ into pJW1+4 produced plasmid o (oocyte). The oocyte 5S RNA gene within $o \psi$ was replaced with the somatic 5S RNA gene from pXls11 to create a new plasmid, $s \rightarrow 0 \psi$, identical to o $\psi$ except for single base differences at eight positions within the 5S RNA coding sequence. Plasmid $s \rightarrow 0 \psi$ was constructed by first exchanging the $5^{\prime}$ flanking sequences via the HaeIII site at position 8 of the coding sequence and then exchanging the $3^{\prime}$ flanking sequences via the FokI site at position 94. Because of the existence of numerous HaeIII sites within the plasmids, the interchange of sequences at the desired HaeIII site (position 8) was accomplished as follows: plasmids $0 \psi$ and $s$ were linearized by partial digestion with HaeIII in the presence of $250 \mu \mathrm{M}$ ethidium bromide. The linear DNAs were electrophoretically purified and digested with HindIII and EcoRI, respectively. Appropriate DNA fragments (the HindIII-HaeIII fragment derived from the $5^{\prime}$ region of o $\psi$ and the HaeIII-EcoRI fragment derived from the $3^{\prime}$ region of s) were electrophoretically purified and ligated into the vector to produce an intermediate plasmid. This plasmid was then used to switch the $3^{\prime}$ flanking sequences via the FokI site at position 94 , yielding the switch clone $s \rightarrow 0 \psi \psi$ containing a somatic 5S RNA gene precisely positioned within oocytetype, A+T-rich flanking sequences. The pseudogene of $\mathrm{s} \rightarrow \mathrm{O} \psi$ was removed by replacing the FokI-EcoRI fragment with the corresponding fragment from $o$. The resulting plasmid, $s \rightarrow 0$, was identical to plasmid o except for single base pair differences at eight positions within the 5S RNA coding sequence, thus transforming an oocyte 5S RNA gene into a somatic 5S RNA gene.

Oocyte microinjection. For each sample, a total of $5 \mathrm{ng}$ of plasmid DNA in $25 \mathrm{nl}$ was injected into the germinal vesicle of each of 20 oocytes. After $5 \mathrm{~h}, 250 \mathrm{nCi}$ of $\left[\alpha^{-32} \mathrm{P}\right] \mathrm{GTP}$ was injected into the cytoplasm of each oocyte. After overnight incubation at $18^{\circ} \mathrm{C}$, the oocytes were pooled and homogenized in $400 \mu$ l of $50 \mathrm{mM}$ Tris hydrochloride ( $\mathrm{pH} 7.5)-50 \mathrm{mM}$ $\mathrm{NaCl}-10 \mathrm{mM}$ EDTA-0.5\% sodium dodecyl sulfate-proteinase $\mathrm{K}(250 \mu \mathrm{g} / \mathrm{ml})$. After incubation for $1 \mathrm{~h}$ at $37^{\circ} \mathrm{C}$, the samples were extracted twice with an equal volume of phenol-chloroform $(1: 1, \mathrm{vol} / \mathrm{vol})$, and the nucleic acids were precipitated with ethanol. The samples were redissolved in $20 \mu$ l of formamide and heated at $100^{\circ} \mathrm{C}$ for $2 \mathrm{~min}$ before 10 $\mu l$ was loaded onto an extensively preelectrophoresed $12.5 \%$ polyacrylamide gel containing $4 \mathrm{M}$ urea and $90 \mathrm{mM}$ Trisborate (pH 8.3)-2.5 mM EDTA. Electrophoresis was done overnight with $90 \mathrm{mM}$ Tris-borate-2.5 mM EDTA as the running buffer. This partially denaturing gel separates the oocyte and somatic 5S RNAs even though they are of the same length (31). In the $4 \mathrm{M}$ urea gels used in our study the oocyte 5S RNA ran more slowly than did the somatic 5S RNA. This was the reversed order of migration relative to the one observed by Wakefield and Gurdon (31). The difference was probably due to the absence of a stacking gel in our version of the $4 \mathrm{M}$ urea gel system. Oocytes for microinjection were isolated from fragments of $X$. laevis ovaries by digestion with $2.5 \mathrm{mg}$ of collagenase per $\mathrm{ml}$ in ORII buffer $(83 \mathrm{mM} \mathrm{NaCl}, 2.5 \mathrm{mM} \mathrm{KCl}, 1 \mathrm{mM} \mathrm{MgCl}, 1 \mathrm{mM}$
$\mathrm{NaH}_{2} \mathrm{PO}_{4}, 5 \mathrm{mM}$ sodium- $N$-2-hydroxyethylpiperazine- $N$ '-2ethanesulfonic acid [HEPES] [pH 7.6]). After extensive washing with ORII, the oocytes were transferred to MBS-H buffer [ $88 \mathrm{mM} \mathrm{NaCl}, 1 \mathrm{mM} \mathrm{KCl}, 2.4 \mathrm{mM} \mathrm{NaHCO}_{3}, 0.82 \mathrm{mM}$ $\mathrm{MgSO}_{4}, 0.33 \mathrm{mM} \mathrm{Ca}\left(\mathrm{NO}_{3}\right)_{2}, 0.41 \mathrm{mM} \mathrm{CaCl}_{2}, 10 \mathrm{mM}$ sodiumHEPES (pH 7.6), $10 \mathrm{mg}$ of penicillin per $\mathrm{ml}, 10 \mathrm{mg}$ of streptomycin per $\mathrm{ml}$. Subsequent microinjections and incubations were done in MBS-H buffer.

Transcription in the oocyte nuclear extract. The oocyte nuclear extract was prepared by the method of Birkenmeier et al. in $\mathrm{J}$ buffer with 1\% PVP-360 (Sigma Chemical Co.) starting with stage 5 and 6 oocytes (2). Nine microliters of oocyte nuclear extract, corresponding to approximately nine manually isolated germinal vesicles, was mixed with $5 \mu \mathrm{l}$ of $30 \mathrm{mM}$ sodium-HEPES (pH 7.6)-70 mM KCl-14 mM $\mathrm{MgCl}_{2}-2 \mathrm{mM}$ dithiothreitol-20 $\mu \mathrm{M} \mathrm{ZnCl}$ containing $100 \mathrm{ng}$ of plasmid DNA and incubated at room temperature $\left(\sim 22^{\circ} \mathrm{C}\right)$ for $15 \mathrm{~min}$. Next, $10 \mu \mathrm{Ci}$ of $\left[\alpha-{ }^{32} \mathrm{P}\right] \mathrm{GTP}$ and additional nucleoside triphosphates in $5 \mu$ l of $30 \mathrm{mM}$ sodium-HEPES (pH 7.6)-70 mM KCl-2 mM dithiothreitol-10\% glycerol were added. The final concentrations of added nucleoside triphosphates in the 19- $\mu$ l reaction were as follows: ATP, 1 $\mathrm{mM}$; CTP, $0.4 \mathrm{mM}$; UTP, $0.2 \mathrm{mM}$; and GTP, $20 \mu \mathrm{M}$. After a 2 -h incubation at room temperature, 2 volumes of stop buffer (50 mM Tris hydrochloride [pH 7.5], $50 \mathrm{mM} \mathrm{NaCl}, 15$ $\mathrm{mM}$ EDTA, $0.6 \%$ sodium dodecyl sulfate, $400 \mu \mathrm{g}$ of proteinase $\mathrm{K}$ per $\mathrm{ml}$ ) were added. The samples were incubated at $37^{\circ} \mathrm{C}$ for $1 \mathrm{~h}$, extracted once with phenol-chloroform, precipitated with ethanol, dissolved in $20 \mu$ l of formamide, and electrophoresed on a partially denaturing gel as described above.

Transcription in the oocyte $\mathbf{S 1 5 0}$ extract. The $\mathrm{S} 150$ extract was prepared by the method of Glikin et al. (12). This extract was prepared with a mixture of oocytes from all stages of development. However, the bulk of the oocytes consisted of the larger, stage 5 and 6 oocytes. Oocyte $S 150$ extract $(20 \mu \mathrm{l})$ was mixed with $10 \mu \mathrm{l}$ of $36 \mathrm{mM}$ sodium-HEPES ( $\mathrm{pH} 7.6$ )-84 $\mathrm{mM} \mathrm{KCl}-21 \mathrm{mM} \mathrm{MgCl}_{2}-2.4 \mathrm{mM}$ dithiothreitol-24 $\mu \mathrm{M}$ $\mathrm{ZnCl}_{2}-9 \%$ glycerol containing $100 \mathrm{ng}$ of plasmid DNA and including the components listed below so that their concentrations in the resulting 30- $\mu$ l reaction were as follows: ATP, $3 \mathrm{mM}$; creatine phosphate, $8 \mathrm{mM}$; CTP, $0.5 \mathrm{mM}$; UTP, 0.2 $\mathrm{mM}$; and GTP, $20 \mu \mathrm{M}$. After a 1-h incubation, $10 \mu \mathrm{Ci}$ of $\left[\alpha-{ }^{32} \mathrm{P}\right] \mathrm{GTP}$ was added in $3 \mu \mathrm{l}$ of $30 \mathrm{mM}$ sodium-HEPES $(\mathrm{pH}$ 7.6)-70 mM KCl-18 mM $\mathrm{MgCl}_{2}-2 \mathrm{mM}$ dithiothreitol-20 $\mu \mathrm{M}$ $\mathrm{ZnCl}_{2}-8 \%$ glycerol. After an additional $2 \mathrm{~h}$ of incubation at room temperature, 2 volumes of stop buffer were added and the transcription products were isolated and analyzed as described above.

DNase I footprinting. Plasmids $s \rightarrow 0$ and o were digested with $E c o$ RI and bacterial alkaline phosphatase, labeled with $\left[\gamma-{ }^{32} \mathrm{P}\right] \mathrm{ATP}$ and T4 polynucleotide kinase, and recircularized by ligation with T4 DNA ligase at room temperature, at a DNA concentration of $4 \mu \mathrm{g} / \mathrm{ml}$. Approximately $80 \%$ of the plasmid DNAs in the resulting samples were in a closed circular configuration. Transcription assay samples $(40 \mu \mathrm{l})$ containing $100 \mathrm{ng}$ of plasmid DNA and $20 \mu$ l of oocyte S150 extract were prepared essentially as described above. These samples included nucleoside triphosphates and all exogenously added components necessary for transcription. After $3.5 \mathrm{~h}$ at room temperature, either $1.2 \mu \mathrm{g}$ or $0.8 \mu \mathrm{g}$ of DNase I (DPRF grade; Worthington Diagnostics) in $10 \mu \mathrm{l}$ of transcription buffer was added. Control digestions of DNA alone, in which transcription buffer replaced the oocyte $S 150$ extract, were done with either 60 or $30 \mathrm{ng}$ of DNase I. DNase I digestions were done for $1 \mathrm{~min}$ and were stopped by the 


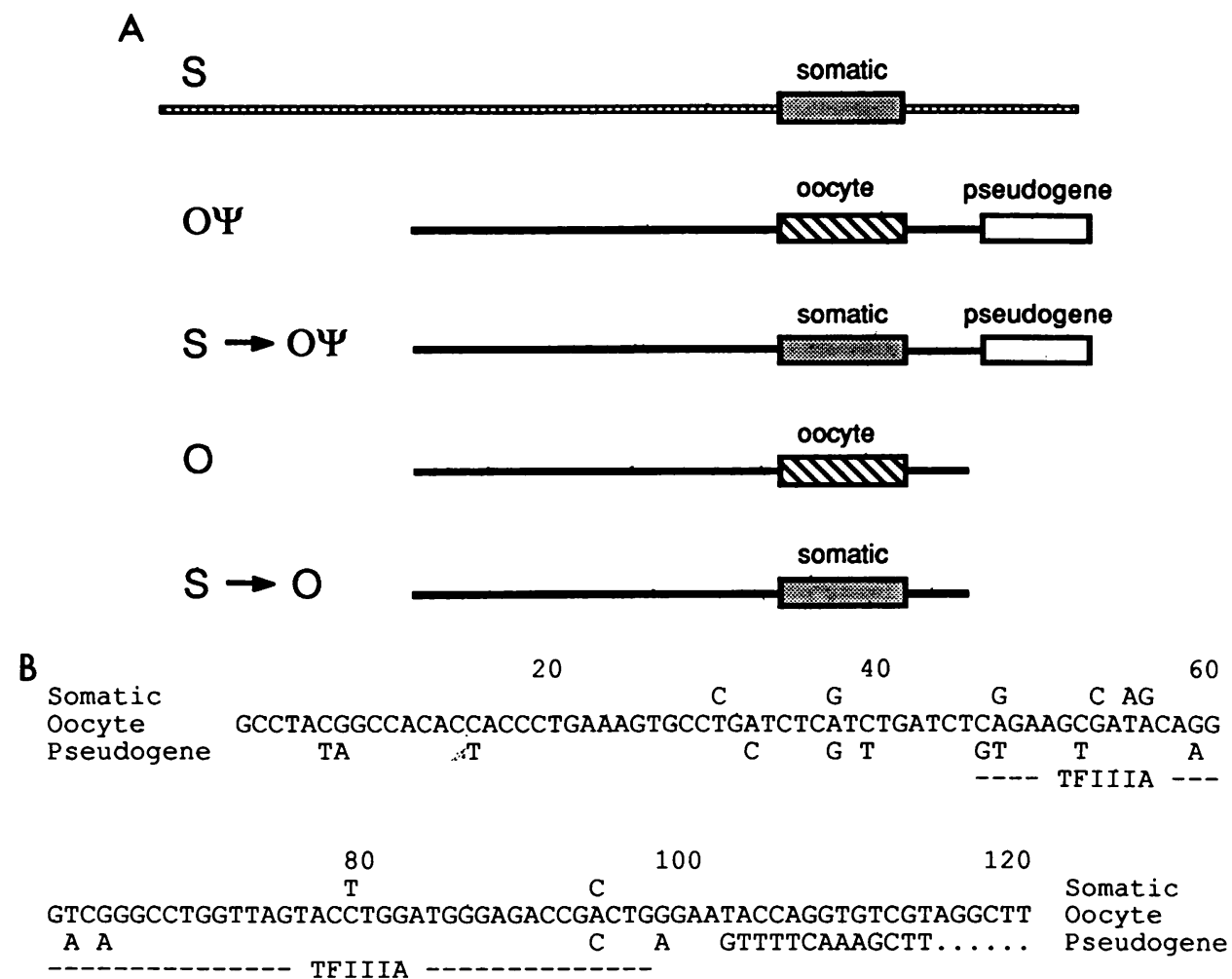

FIG. 1. Clones containing 5S RNA genes of $X$. laevis. (A) Diagram showing the relationship between the 5S RNA genes and their flanking sequences. The natural (wild-type) arrangements are represented by clones labeled s (somatic) and o $\psi$ (oocyte-pseudogene). The $\mathrm{G}+\mathrm{C}$-rich sequences $(43 \% \mathrm{~A}+\mathrm{T})$ naturally found surrounding somatic 5S RNA genes are denoted by hatched lines. The A+T-rich sequences (76\% $A+T)$ naturally found surrounding oocyte 5S RNA genes are denoted by filled lines. The rectangles represent 5S RNA coding sequences. Transcription occurs from left to right in all genes. Spacer DNA regions are drawn approximately to scale, relative to the length of the 5S RNA gene (120 base pairs). For other designations, see Materials and Methods. (B) Nucleotide sequences of 5S RNA genes. The sequences of the noncoding DNA strands are given $(2,20)$. Only the differences from the oocyte gene sequence are shown for the somatic and pseudogene sequences. The positions marked by dots at the $3^{\prime}$ end of the pseudogene are occupied by vector sequences in the plasmids described here. The binding site of TFIIIA as defined by nuclease footprinting is indicated.

addition of $50 \mu$ l of $50 \mathrm{mM}$ Tris hydrochloride (pH 8)-20 $\mathrm{mM}$ EDTA-1\% sodium dodecyl sulfate-Proteinase $\mathrm{K}(200$ $\mu \mathrm{g} / \mathrm{ml})$. After $1 \mathrm{~h}$ at $37^{\circ} \mathrm{C}, 20 \mu \mathrm{l}$ of $5 \mathrm{M}$ potassium acetate was added, and the samples were extracted with chloroform, reextracted with phenol-chloroform, and precipitated with ethanol. Digestion with $M b o$ II and EcoRI released two end-labeled, full-length fragments, i.e., fragments derived from plasmids lacking double-stranded cuts by DNase I. The DNase I digestion products of the larger full-length fragment, which contained the 5S RNA coding region, were electrophoresed in an $8.3 \mathrm{M}$ urea-15\% polyacrylamide-90 $\mathrm{mM}$

Tris-borate-

$2.5 \mathrm{mM}$ EDTA gel. (The smaller full-length fragment and its DNase I digestion products ran off the bottom of the gel.) Footprints of purified TFIIIA (a gift of J. Blanco) were obtained by using labeled plasmid DNA which had previously been digested with MboII and EcoRI. Either 50 or 15 ng of DNase I was used for these digestions.

\section{RESULTS}

Transcription of $5 S$ RNA genes. To investigate the possible effects of flanking sequences surrounding the 5S RNA coding regions on the differential transcription of the two families of 5S RNA genes, we constructed specific switch DNA clones. These switch clones consisted of somatic $5 S$ RNA genes positioned within the A+T-rich flanking se- quences normally present around the oocyte-type genes (Fig. 1). For example, the pair of DNA clones oocyte (o) and $s \rightarrow 0$ have the same total number of base pairs, with the sequence differences indicated in Fig. 1B, such that 0 contains an oocyte 5S RNA gene, and $s \rightarrow 0$ contains a somatic 5S RNA gene. Both genes reside within the A+Trich context of flanking sequences specific for the oocytetype gene (Fig. 1A).

These constructs were microinjected into the nuclei (germinal vesicles) of Xenopus oocytes, and the purified transcription products were analyzed by electrophoresis in a partially denaturing gel (31), which separated the identically sized oocyte and somatic 5S RNAs on the basis of slight differences in RNA conformation arising from their few sequence differences (Fig. 2). Microinjection of a mixture of o (oocyte) and s (somatic) plasmids at a 4 to 1 molar ratio into the nucleus of the oocyte demonstrated an " 10-fold" preference for transcription of the somatic over the oocyte 5S RNA genes (Fig. 2, lane b). These results are similar to those previously reported $(7,9)$. The $\sim 10$-fold preference for transcription of the somatic 5S RNA genes in oocytes is significantly smaller than the preference characteristic of developing embryos, which show an $\sim 50$-fold preference for transcription of somatic 5S RNA genes just after the midblastula transition $(31,34)$. This transcriptional bias further increases during development such that the bias in adult somatic cells is at least 1,000 -fold (17). 


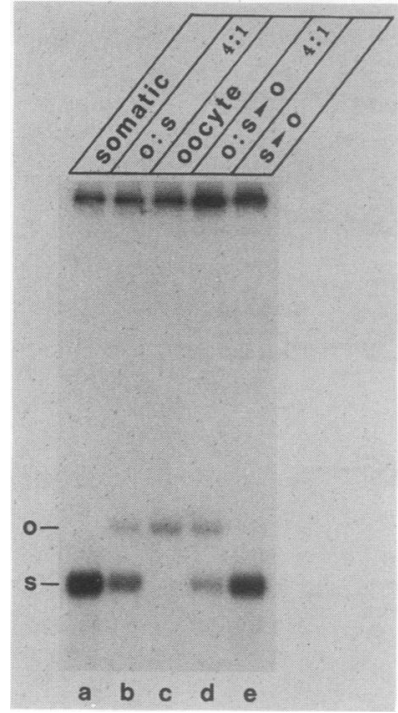

FIG. 2. Transcription products of 5S RNA genes microinjected into $X$. laevis oocytes. The plasmid DNAs microinjected in each case are indicated. Abbreviations: o:s 4:1, a mixture of plasmids o and $s$ at a 4 to 1 molar ratio; o:s $>04: 1$, plasmids o and $s>0$ at a 4 to 1 molar ratio. An autoradiogram of a partially denaturing gel that separates the somatic and oocyte 5S RNAs is shown. The 5S RNAs marked $s$ and $o$ have the same electrophoretic mobility in a completely denaturing gel.

To test the effect of flanking sequences on this ratio, a mixture of $o$ and $s \rightarrow 0$ plasmid DNAs (Fig. 1A) was microinjected into oocytes (Fig. 2, lane d). These two clones contain different types of 5S RNA genes but exactly the same A+T-rich flanking sequences characteristic for the oocyte-type genes. Thus the difference between lanes $b$ and d of Fig. 2 is that the $G+C$-rich flanking sequences of the somatic 5S RNA gene in the experiment of lane $b$ have been replaced by $A+T$-rich flanking sequences in the experiment of lane $d$. The ratio of 5S RNA transcripts in lane $d$ of Fig. 2 shows that the microinjected somatic 5S RNA gene is still preferentially transcribed but that switching the flanking sequences has reduced this preference approximately threefold. This reduced transcriptional preference may be due in part to inefficient termination at the $3^{\prime}$ end of the 5S RNA gene when $\mathrm{A}+\mathrm{T}$-rich flanking sequences are present (see below) and to the subsequent selective degradation of the improperly terminated RNAs in the oocyte. Irrespective of the explanation, the effect of switching the flanking sequences on the relative rates of 5S RNA gene transcription is relatively small, at least with microinjection into oocytes.

In vitro transcription of mixtures of somatic and oocyte $5 \mathrm{~S}$ RNA genes in an extract prepared from isolated oocyte nuclei (Fig. 3A) yielded results similar to those obtained in oocyte microinjection experiments $(3,7,33)$. The efficient transcription of the 5S RNA pseudogene is shown in Fig. 3A, lanes $b$ and $c(22)$. Three transcripts were produced when plasmid o was used as the template (Fig. 3A, lane d), even though this plasmid contained a single oocyte 5S RNA gene (Fig. 1A). The multiple transcripts were produced because the $3^{\prime}$ flanking sequences of the $X$. laevis oocyte 5S RNA gene inefficiently terminate transcription by RNA polymerase III (3). The two longer transcripts in lane d of Fig. 3A thus resulted from termination at downstream sites. A similar triplet of bands was seen when the oocyte-type coding sequence was replaced by a somatic-type coding sequence, although the triplet of bands had a larger electrophoretic mobility (Fig. 3A, lane e). The two extra bands in lane e of Fig. 3A that were not present in lane a were due to the substitution of the efficient termination signal normally found $3^{\prime}$ to the somatic 5S RNA gene with the leaky, oocyte-type terminator described above.

In vitro transcription in the oocyte nuclear extract resulted in the production of $\sim 10$-fold more somatic than oocyte $5 S$ RNAs on a per gene basis (Fig. 3A, lanes $f, g$, and $h$ ). These reactions contained pairs of plasmid DNAs which differed exclusively in their 5S RNA coding sequence. Other experiments with mixtures of plasmids $o$ and $s$, in which the $5 S$ RNA genes are surrounded by their wild-type flanking sequences, gave similar results (data not shown). Thus, the $\sim 10$-fold-greater preference for transcription of somatic over oocyte 5S RNA genes in the oocyte nuclear extract was not highly dependent on the nature of the flanking sequences. The results of experiments similar to those of lanes $f, g$, and $h$ of Fig. 3A are shown in lanes i, j, and k, except that vector DNA was used as a competitor instead of the plasmid o, which contains an oocyte 5S RNA gene. The total amount of DNA was the same in all reactions and the number of somatic 5S RNA genes was the same in the corresponding reactions (Fig. $3 A$, lanes $f$ and $i, g$ and $j$, and $h$ and $k$ ). The amount of somatic 5S RNA synthesized was greatly reduced in lanes $\mathrm{f}, \mathrm{g}$, and $\mathrm{h}$, when oocyte 5S RNA genes were also present, relative to that in the corresponding lanes $\mathrm{i}, \mathrm{j}$, and $\mathrm{k}$

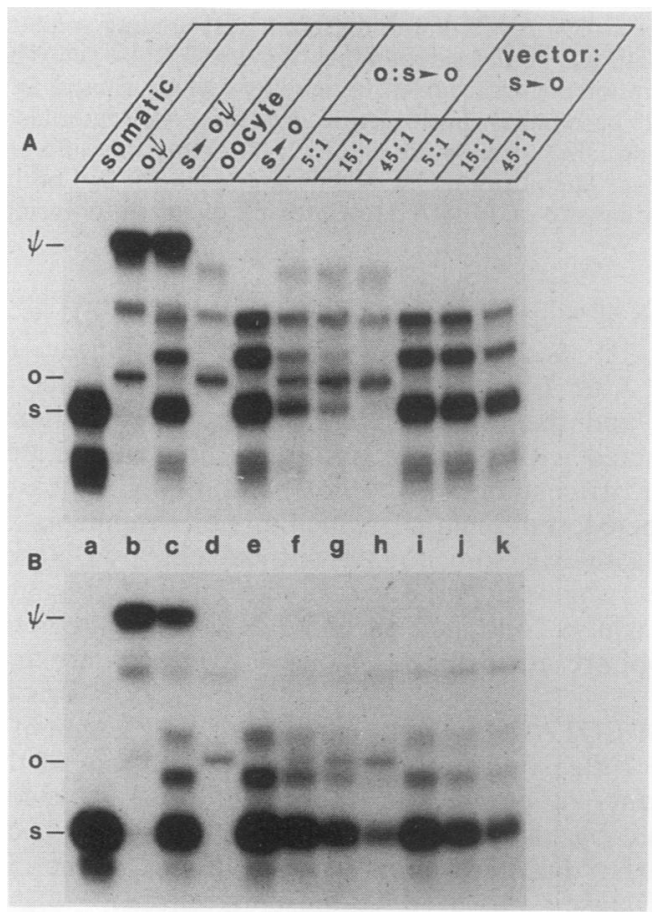

FIG. 3. In vitro transcription of 5S RNA genes in $X$. laevis oocyte extracts. (A) Transcription products from a nuclear (germinal vesicle) extract; (B) transcription products from an oocyte S150 extract. For each lane, the plasmid DNAs included in the reaction are indicated. Each reaction contained a total of $100 \mathrm{ng}$ of plasmid DNA. For example, the transcripts in lane $\mathrm{g}$ came from reactions containing $93.7 \mathrm{ng}$ of plasmid $o$ and $6.3 \mathrm{ng}$ of plasmid $\mathrm{s} \rightarrow \mathrm{O}$ so that the total amount of DNA was $100 \mathrm{ng}$, and the molar ratio of added plasmids was 15 to 1 . Autoradiograms of partially denaturing gels are shown. 
of Fig. 3A, when vector DNA was used as competitor. This result was an expected one because the oocyte 5S RNA genes present in reactions of Fig. 3A, lanes $f, g$, and $h$ were competing for components in the extract required for transcription of both types of 5S RNA genes. What was unexpected, however, was that the relative reduction in the transcription of somatic 5S RNA genes was larger than the corresponding increase in the transcription of oocyte $5 \mathrm{~S}$ RNA genes. One interpretation of this result is that the oocyte 5S RNA genes were competing for the binding of transcriptional factors but were not using these factors, once bound, as efficiently as the somatic 5S RNA genes for the production of 5S RNAs.

Transcription of somatic 5S RNA genes was thus favored $\sim 10$-fold more than transcription of oocyte 5S RNA genes in assays using both microinjection into oocyte nuclei and in vitro transcription in an oocyte nuclear extract. These results are in general agreement with those previously reported $(3,7,9,33)$. The relative transcriptional activity of the oocyte 5S RNA genes after microinjection and in the oocyte nuclear extract suggests that these two experimental systems resemble the unperturbed in vivo state during oogenesis when the endogeneous genes for both somatic and oocyte 5S RNA are active. This is in contrast to the strong transcriptional bias in late embryos, in which the preference for transcription of somatic over oocyte 5S RNA genes is greater than 100 -fold $(31,34)$.

In vitro transcription in a whole-oocyte extract strongly favors somatic-type 5S RNA genes. We found that an extract derived from whole oocytes, called the oocyte $\$ 150$ extract (12), transcribed oocyte-type 5S RNA genes extremely inefficiently while allowing active transcription of the somatictype 5S RNA genes. The preference for transcription of somatic over oocyte 5S RNA genes was $\sim 100$-fold in the $\mathrm{S} 150$ extract (Fig. 3B, lanes $\mathrm{f}, \mathrm{g}$, and $\mathrm{h}$ ). This transcriptional preference (Fig. 3B) is an order of magnitude higher than the bias observed either in oocyte microinjection experiments (Fig. 2) or for an oocyte nuclear extract (Fig. 3A). The remarkably high degree of in vitro discrimination between somatic and oocyte 5S RNA genes in the S150 transcription system (Fig. 3B) thus mimicked the differential expression of these genes in vivo, either in developing normal embryos or in syncytial embryos after the injection of cloned 5S RNA genes (7).

Figure $3 \mathrm{~B}$ shows the 5S RNA transcription products obtained with the oocyte S150 extract. Compare these transcripts with the transcripts produced in the oocyte nuclear extract (Fig. 3A). The DNA templates added to the reactions were identical for each lane (Fig. 3A and B). The only essential difference between the corresponding reactions for the upper and lower panels of Fig. 3 was the nature of the extract used. For instance, reactions for lane $h$ in Fig. $3 \mathrm{~A}$ and $\mathrm{B}$ contained a 45-fold molar excess of oocyte over somatic 5S RNA genes. With this mixture of DNAs, the oocyte nuclear extract (Fig. 3A, lane h) produced virtually no somatic 5S RNAs, but there were at least twice as many somatic as oocyte 5S RNAs made in the oocyte $\mathrm{S} 150$ extract from the same mixture of DNA templates (Fig. 3B, lane h). Thus, the oocyte S150 extract showed at least a 100 -fold preference for the transcription of somatic over oocyte $5 \mathrm{~S}$ RNA genes.

The accurate and efficient transcription of the somatic $5 \mathrm{~S}$ RNA genes in the $\mathrm{S} 150$ extract is an argument against trivial explanations for the inactivity of the oocyte 5S RNA genes in this in vitro system. In addition, pulse-chase experiments directly showed that the oocyte and somatic 5S RNAs were equally stable in the oocyte $\mathrm{S} 150$ extract. No degradation of either of the newly synthesized 5S RNAs was observed during a 2-h chase in the extract (data not shown). Thus, differential stability cannot account for the differential accumulation of the two types of 5S RNA during transcription in the oocyte S150 extract. Furthermore, although the total level of 5S RNA transcription was significantly reduced when the total concentration of SS RNA genes in the S150 extract was reduced by up to 16 -fold, no change in the $\sim 100$-fold transcriptional bias was observed under these conditions (data not shown). Thus, the highly preferential transcription of the somatic versus oocyte 5S RNA genes in the $\mathrm{S} 150$ extract was unlikely to be due to competition for a limiting factor in the extract.

Because the pair of plasmids (o and $s \rightarrow 0$, Fig. 1) used as templates (Fig. 3, lanes $\mathrm{f}, \mathrm{g}$, and $\mathrm{h}$ ) differed exclusively within the 5S RNA coding region, we conclude that the observed transcriptional bias was a result of sequence differences within the coding regions of the 5S RNA genes and was not caused solely by the flanking sequences. However, experiments designed to examine the effect of switching the flanking sequences showed that the transcriptional bias favoring somatic over oocyte-type 5S RNA genes is decreased approximately threefold when the wild-type sequences normally found adjacent to the somatic-type $5 \mathrm{~S}$ RNA genes are replaced by the A+T-rich oocyte-type flanking sequences (unpublished data). The effect of flanking sequences on the transcriptional bias in the oocyte $\mathbf{S 1 5 0}$ extract was thus similar to that observed using microinjection into oocytes (Fig. 2).

The plasmid o $\psi$ contains both an oocyte 5S RNA gene and a pseudogene separated by less than 100 base pairs of DNA (Fig. 1A). Even though the pseudogene is actively transcribed, the oocyte 5S RNA gene is largely inactive in the oocyte S150 extract (Fig. 3B, lane b). In addition, when the oocyte 5S RNA gene is converted into the somatic 5S RNA gene (plasmid $s \rightarrow O \psi$ ), keeping the flanking sequences and the pseudogene the same (Fig. 1A), both the somatic 5S RNA gene and the pseudogene are actively transcribed (Fig. 3B, lane c). Thus, the level of transcription of two 5S RNA genes located quite close to each other on the same plasmid could be regulated independently. This result suggests that the differential regulation of 5S RNA genes, in this in vitro system, is not based on relatively large domains of chromatin having either transcriptionally active or inactive configurations.

TFIIIA bound to both active and inactive 5S RNA genes. We found that TFIIIA was bound to the internal control region of an oocyte 5S RNA gene in an oocyte S150 extract under conditions in which the somatic-type 5S RNA gene was transcribed at least 100 -fold more efficiently than its oocyte-type counterpart. Figure 4 illustrates the DNase I digestion patterns of internally prelabeled, closed circular plasmids o (Fig. 4, lanes $\mathrm{k}$ and $\mathrm{l}$, denoted $\mathrm{S} 150, \mathrm{o}$ ) and $\mathrm{s} \rightarrow 0$ (Fig. 4, lanes $\mathrm{m}$ and $\mathrm{n}$, denoted $\mathrm{S} 150, \mathrm{~s}$ ) during incubation in the oocyte S150 extract under transcription conditions. Compare these digestion patterns (lanes $\mathbf{k}$ through $\mathbf{n}$ ) with those of free DNA (denoted DNA), with the TFIIIA footprint observed with either highly purified TFIIIA (denoted TFIIIA) or the TFIIIA present in a fraction from a phosphocellulose column (denoted PC). These results show that almost all, if not all, of the 5S RNA genes of both the somatic and oocyte types are specifically associated with TFIIIA in the S150 extract. A 5S RNA gene transcription complex, consisting of at least two transcription factors in addition to TFIIIA, has a DNase I footprint distinct from 


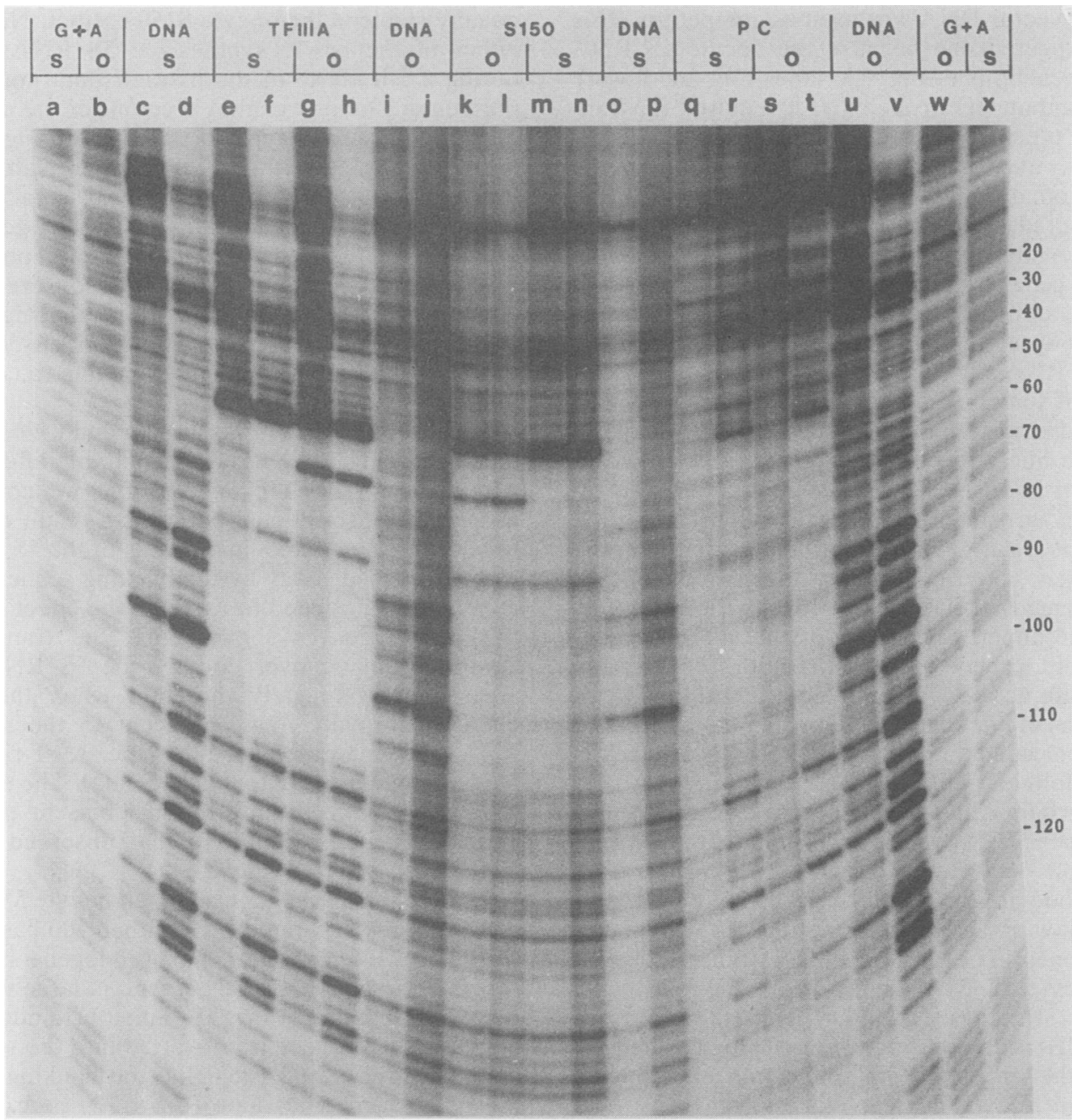

FIG. 4. DNase I footprinting of 5S RNA genes in the oocyte $\mathrm{S} 150$ extract. DNase I digestion patterns of two plasmids, $s \rightarrow 0$ and $o$, marked $\mathrm{s}$ and $\mathrm{o}$, respectively, which differ only in their 5S RNA coding regions are shown. Lanes: $\mathrm{k}$ through $\mathrm{n}$, digestion patterns of internally prelabeled, closed circular DNAs incubated in the oocyte S150 extract under transcription conditions; $c$ and $d, i$ and $j, o$ and $p$, and $u$ and $\mathrm{v}$, control digestion patterns of free DNA. Lanes $\mathrm{i}, \mathrm{j}, \mathrm{o}$, and $\mathrm{p}$, represent reactions identical to those in lanes $k$ through $n$ except that transcription buffer was included instead of oocyte $S 150$ extract, and less DNase I was used. Lanes: TFIIIA, footprints observed with purified TFIIIA. Lanes: PC, footprints observed with a TFIIIA-containing fraction obtained by phosphocellulose chromatography of the S150 extract. Pairs of lanes differ in the amount of DNase I used. The numbers on the right of the figure refer to the 5S RNA coding region (see the legend to Fig. 1B) as defined by the G+A markers (19).

that of TFIIIA alone (32). Under the transcription conditions in the oocyte S150 extract, only a TFIIIA footprint was detected (Fig. 4), presumably because only a fraction of the input template was actually transcribed. Even though both genes were complexed with TFIIIA in this oocyte extract, the somatic 5S RNA genes were actively transcribed but the oocyte 5S RNA genes were not. This implies that the selective transcriptional inactivity of the oocyte-type $5 \mathrm{~S}$ RNA genes observed in this extract is not caused by the absence of TFIIIA at the internal control regions of the oocyte-type 5S RNA genes.

\section{DISCUSSION}

Current models for the differential regulation of 5S RNA gene families during development are based on the premise that the binding of TFIIIA to the internal control region of a
5S RNA gene is the critical factor in determining the transcriptional activity of that gene $(4,7,9,13,25)$. Because TFIIIA is necessary for transcription, it has been assumed that binding of TFIIIA is also sufficient for transcription, provided that other essential components of the transcription complex are also available. We have found this assumption to be incorrect, at least for the $\mathbf{S} 150$ in vitro transcription system. The fact that transcriptionally inactive oocyte 5S RNA genes can have TFIIIA bound to the internal control region implies that the critical factor, the component of the system which actually sets the switch, is neither TFIIIA binding per se nor the quantitative modulation of the amount of TFIIIA.

Our findings, however, do not define the critical factor responsible for the high transcriptional bias in favor of the somatic 5S RNA genes in the $\mathrm{S} 150$ extract. They indicate only that it is not TFIIIA binding per se and that the inactivity of the oocyte 5S RNA gene does not depend solely 
on the nature of the flanking sequences or on direct competition with the somatic 5S RNA genes for a limiting factor in the extract.

The finding that an extract prepared from whole oocytes (as opposed to a nuclear oocyte extract) should display the pattern of regulation of 5S RNA gene expression characteristic not of oogenesis, but of much later stages of development, may be related to the partitioning of specific components between the nucleus and cytoplasm of an oocyte. Extracts made from the nuclei of oocytes do display the pattern of 5S RNA regulation characteristic of the stage of development represented by the oocytes. During the preparation of the $S 150$ extract from whole oocytes, the cytoplasmic and nuclear components are mixed (12). This may bring the transcription apparatus of the oocyte nucleus into contact with some components which were previously sequestered in the cytoplasm of the oocyte and which would normally be allowed nuclear access only at a later stage of development.

One interesting possibility is that TFIIIA itself may be modified in the oocyte cytoplasm such that one form of TFIIIA, found in the oocyte nucleus, activates both somatic and oocyte 5S RNA genes, whereas the other form, found in embryos and in the oocyte cytoplasm, activates somatic $5 \mathrm{~S}$ RNA genes but not oocyte 5S RNA genes. In this case, TFIIIA would be acting as an activator for somatic 5S RNA genes and as either a repressor or an activator for oocyte $5 \mathrm{~S}$ RNA genes, depending on the state of modification of TFIIIA. A modified TFIIIA-oocyte 5S RNA gene complex could bind additional transcription factors or RNA polymerase III relatively poorly, resulting in less-efficient transcription. We are not aware of an experimental precedent for such a mechanism of differential gene regulation. A partial precedent exists for the conversion of a regulatory gene product into a transcriptional activator by posttranslational modification. In this case, methylation of the Ada protein of Escherichia coli converts this protein into an activator of transcription (30). TFIIIA modification need not be covalent and could arise from the binding of either another protein or a low-molecular-weight allosteric effector. A mechanistically related possibility, equally consistent with the data, is that some component of the transcriptional complex which interacts with the TFIIIA-5S RNA gene complex is modified in the $S 150$ extract such that it can sense the subtle difference between an oocyte 5S RNA gene-TFIIIA complex and a somatic 5S RNA gene-TFIIIA complex, the difference being due to the few nucleotide sequence divergencies between the two genes (Fig. 1B). Either TFIIIB or TFIIIC is a possible candidate for such a component.

Kmiec et al. have recently proposed a specific model for the differential transcription of 5S RNA genes (15). This model involves TFIIIA-dependent transcriptional activation of 5S RNA genes through alterations in their chromatin structure. Our results contradict this model. Briefly, we found that both somatic- and oocyte-type 5S RNA genes were saturated with TFIIIA in the oocyte S150 extract (the same extract used by $\mathrm{Kmiec}$ et al.), yet we observed considerable differences in the transcriptional activities of the two types of 5S RNA genes. Furthermore, we found that the rate of negative supercoiling (the rate of decrease in linking number) of the template plasmid DNAs in the course of incubation in the oocyte $\mathbf{S} 150$ extract under transcription conditions was the same for plasmids containing either actively transcribed somatic 5S RNA genes or relatively inactive oocyte 5S RNA genes (data not shown). These latter experiments, however, could not rule out the possibility that the transcriptionally active fraction of the template DNA has an altered structure which may not be detected by this supercoiling assay which examines the bulk of the plasmid.

The results of measurements of the levels of TFIIIA protein during Xenopus development (28) are not inconsistent with the binding of TFIIIA to both somatic and oocyte 5S RNA genes during embryogenesis. Shortly after the resumption of transcription that follows the complete transcriptional block during the first 12 cleavage divisions, the preference for transcription of somatic over oocyte 5S RNA genes is $\sim 50$-fold $(31,34)$. The degree of selective repression of the oocyte 5S RNA genes increases in the course of subsequent embryonic development. The degree of repression that we have observed in vitro in the oocyte S150 extract $(\mathrm{a} \sim 100$-fold greater preference for transcription of somatic over oocyte 5S RNA genes) and that is also observed by injection of DNAs into coenocytic (syncytial) embryos (7) is similar to the level of repression observed during embryogenesis. Because TFIIIA is bound to both somatic and oocyte 5S RNA genes in the oocyte S150 extract (Fig. 4), we suggest that the pathway of selective repression of oocyte 5S RNA genes during embryogenesis may involve a complex of a 5S RNA gene with TFIIIA. If so, contrary to predictions of other models for the differential regulation of these two gene families, TFIIIA would be found bound to both oocyte and somatic 5S RNA genes in embryos after the midblastula transition. This prediction is directly testable.

In adult somatic cells, the situation appears to be different. The preference for transcription of somatic over oocyte $5 \mathrm{~S}$ RNA genes is at least 1,000-fold-greater in Xenopus somatic cells (17), at least an order of magnitude greater than the preference characteristic for the early stages of embryogenesis. In addition, there is not enough TFIIIA in somatic cells to bind all of the 5S RNA genes (28). In somatic cells, the early replication of the somatic-type genes and the late replication of the oocyte-type genes may provide a mechanism whereby limiting amounts of TFIIIA are available only to the somatic-type genes $(10,13,14)$. Thus, although the transcriptional switch may function with TFIIIA bound to the gene, as suggested by our findings, the sustained repression of oocyte 5S RNA genes in somatic cells may involve chromatin structures lacking TFIIIA.

\section{ACKNOWLEDGMENTS}

We thank D. Bogenhagen, D. Brown, D. Setzer, and J. Wang for recombinant DNA plasmids, J. Blanco for purified TFIIIA, and J. P. McGrath for comments on the manuscript. We also thank $J$. Schwager for his advice and gifts of numerous $X$. laevis.

This work was supported by Public Health Service grants GM33401 and CA43309 from the National Institutes of Health to A.V. and grant GM26453 from the National Institute of General Medical Sciences and grant FRA292 from the American Cancer Society to J.G. L.P. was supported by a fellowship from the Damon Runyon-Walter Winchel Cancer Fund.

\section{LITERATURE CITED}

1. Bieker, J. J., and R. G. Roeder. 1984. Physical properties and DNA-binding stoichiometry or a $5 S$ gene-specific transcription factor. J. Biol. Chem. 259:6158-6164.

2. Birkenmeier, E. H., D. D. Brown, and E. Jordan. 1978. A nuclear extract of Xenopus laevis oocytes that accurately transcribes 5S RNA genes. Cell 15:1077-1086.

3. Bogenhagen, D. F., and D. D. Brown. 1981. Nucleotide sequences in Xenopus 5S DNA required for transcription termination. Cell 24:261-270. 
4. Bogenhagen, D. F., W. M. Wormington, and D. D. Brown. 1982. Stable transcription complexes of Xenopus 5S RNA genes: a means to maintain the differentiated state. Cell 28:413-421.

5. Brown, D. D. 1982 . How a simple animal gene works. Harvey Lect. 76:27-44.

6. Brown, D. D. 1984. The role of stable complexes that repress and activate eucaryotic genes. Cell 37:359-365.

7. Brown, D. D., and M. S. Schlissel. 1985. A positive transcription factor controls the differential expression of two 5S RNA genes. Cell 42:759-767.

8. Engelke, D. R., S. Y. Ng, B. S. Shastry, and R. G. Roeder. 1980. Specific interaction of a purified transcription factor with an internal control region of 5S RNA genes. Cell 19:717-728.

9. Gargiulo, G., F. Razvi, and A. Worcel. 1984. Assembly of transcriptionally active chromatin in Xenopus oocytes requires specific DNA binding factors. Cell 38:511-521.

10. Gilbert, D. M. 1986. Temporal order or replication of Xenopus laevis 5S ribosomal RNA genes in somatic cells. Proc. Natl. Acad. Sci. USA 83:2924-2928.

11. Ginsberg, A. M., B. O. King, and R. G. Roeder. 1984. Xenopus 5S gene transcription factor, TFIIIA: characterization of a cDNA clone and measurement of RNA levels throughout development. Cell 39:479-489.

12. Glikin, G. C., I. Ruberti, and A. Worcel. 1984. Chromatin assembly in Xenopus oocytes: in vitro studies. Cell 37:33-41.

13. Gottesfeld, J., and L. S. Bloomer. 1982. Assembly of transcriptionally active 5S RNA gene chromatin in vitro. Cell 28:781791.

14. Guinta, D. R., and L. J. Korn. 1986. Differential order of replication of Xenopus laevis 5S RNA genes. Mol. Cell. Biol. 6:2536-2542

15. Kmiec, E. B., F. Razvi, and A. Worcel. 1986. The role of DNA-mediated transfer of TFIIIA in the concerted gyration and differential activation of the Xenopus 5S RNA genes. Cell 45:209-218.

16. Korn, L. J. 1982. Transcription of Xenopus 5S ribosomal RNA genes. Nature (London) 295:101-105.

17. Korn, L. J., and J. B. Gurdon. 1981. The reactivation of developmentally inert $5 S$ genes in somatic nuclei injected into Xenopus oocytes. Nature (London) 289:461-465.

18. Lassar, A. B., P. L. Martin, and R. G. Roeder. 1983. Transcription of class III genes: formation of preinitiation complexes. Sciences 222:740-748.

19. Maxam, A. M., and W. Gilbert. 1980. Sequencing end-labeled DNA with base-specific chemical cleavages. Methods Enzymol. 65:499-580.

20. Miller, J. R., E. M. Cartwright, G. G. Brownlee, N. V. Fedoroff, and D. D. Brown. 1978. The nucleotide sequence of oocyte 5S DNA in Xenopus laevis. II. The GC-rich region. Cell 13:717725.

21. Miller, J., A. D. McLachlan, and A. Klug. 1985. Repetitive zinc-binding domains in the protein transcription factor IIIA from Xenopus oocytes. EMBO J. 4:1609-1614.

22. Miller, J. R., and D. A. Melton. 1981. A transcriptionally active pseudogene in Xenopus laevis oocyte 5S DNA. Cell 24:829-835.

23. Pelham, H. R. B., and D. D. Brown. 1980. A specific transcription factor that can bind either the 5S RNA gene or 5S RNA. Proc. Natl. Acad. Sci. USA 77:4170-4174.

24. Sakonju, S., and D. D. Brown. 1982. Contact points between a positive transcription factor and the Xenopus 5S RNA gene. Cell 31:395-405.

25. Schlissel, M. S., and D. D. Brown. 1984. The transcriptional regulation of Xenopus 5S RNA genes in chromatin: the roles of active stable transcription complexes and histone $\mathrm{H} 1$. Cell 37:903-913.

26. Segall, J., T. Matsui, and R. G. Roeder. 1980. Multiple factors are required for the accurate transcription of purified genes by RNA polymerase III. J. Biol. Chem. 255:11986-11991.

27. Setzer, D. R., and D. D. Brown. 1985. Formation and stability of the 5S RNA transcription complex. J. Biol. Chem. 260: 2483-2492.

28. Shastry, B. S., B. M. Honda, and R. G. Roeder. 1984. Altered levels of a $5 \mathrm{~S}$ gene-specific transcription factor (TFIIIA) during oogenesis and embryonic development of Xenopus laevis. J. Biol. Chem. 259:11373-11382.

29. Shastry, B. S., S. Y. Ng, and R. G. Roeder. 1982. Multiple factors involved in the transcription of class III genes in Xenopus laevis. J. Biol. Chem. 257:12979-12986.

30. Teo, I., B. Sedwick, M. W. Kilpatrick, T. V. McCarthy, and T. Lindahl. 1986. The intracellular signal for induction of resistance to alkylating agents in E. coli. Cell 45:315-324.

31. Wakefield, L., and J. B. Gurdon. 1983. Cytoplasmic regulation of 5S RNA genes in nuclear-transplant embryos. EMBO J. 2:1613-1619.

32. Wolffe, A. P., E. Jordan, and D. D. Brown. 1986. A bacteriophage RNA polymerase transcribes through a Xenopus 5S RNA gene transcription complex without disrupting it. Cell 33: 381-389.

33. Wormington, W. M., D. F. Bogenhagen, E. Jordan, and D. D. Brown. 1981. A quantitative assay for Xenopus 5S RNA gene transcription in vitro. Cell 24:809-817.

34. Wormington, W. M., and D. D. Brown. 1983. Onset of 5S RNA gene regulation during Xenopus embryogenesis. Dev. Biol. 99:248-257. 